\title{
Pemetaan Daerah Rawan Kerusakan Akibat Gempabumi di Kotamadya Denpasar dan Sekitarnya dengan Menggunakan Analisis Mikrotremor Studi Kasus: Gempabumi Seririt 14
} Juli 1976

\author{
Randi Adzin Murdiantoro ${ }^{1 *}$ Sismanto $^{1}$ dan Marjiyono ${ }^{2}$
}

\begin{abstract}
Abstrak
Tingkat aktifitas seismik di Pulau Bali tergolong tinggi dengan 2 sumber utama gempabumi yaitu aktifitas tektonik sesar naik busur belakang (Back Arc Trust) di bagian utara dan zona subduksi lempeng Indo-Australia yang menunjam ke lempeng Eurasia di bagian selatan. Kotamadya Denpasar dan sekitarnya merupakan pusat pemerintahan Provinsi Bali dengan keberagaman infrastruktur. Penelitian ini telah dilakukan dengan tujuan memetakan daerah rawan kerusakan akibat gempabumi dengan menggunakan pengukuran mikrotremor single station yang diolah menggunakan metode HVSR (Horizontal to Vertical Spectral Ratios) dan mikrotremor array yang dianalisis menggunakan metode SPAC (Spacial Auto Correlation) untuk mendapatkan nilai $v_{s 30}$ (kecepatan gelombang shear sedalam $30 \mathrm{~m}$ ). Hasil penelitian menunjukan Kotamadya Denpasar dan sekitarnya memiliki nilai indeks kerentanan seismik berkisar antara 0,103-33,78, nilai ground shear-strain 7, $00 \times 10^{-6}-2,2 \times 10^{-3}$. Berdasarkan peta, diketahui nilai $v_{s 30}$ berkisar antara 171,32-764,62 m/s. Berdasarkan SNI 1726:2012 dan hasil penelitian, Klasifikasi tingkat resiko gempabumi daerah penelitian menunjukan bahwa Kecamatan Denpasar Selatan memiliki tingkat kerawanan seismik tinggi (kategori resiko I). Tingkat kerawanan seismik menengah berada di Kecamatan Denpasar Barat dan Kecamatan Kuta (kategori I, II, dan III). Daerah dengan tingkat kerawanan seismik rendah berada di Kecamatan Denpasar Timur, Kec. Denpasar Utara, Kec. Kuta Utara, Kec. Mengwi, Kec. Sukawati, Kec. Kediri (kategori I, II, III, dan IV).
\end{abstract}

kata kunci: gempabumi; Denpasar; mikrotremor; HVSR; $v_{s 30}$

\section{Abstract}

The level of seismic activity in the Bali island is high where two earthquakes source area are tectonically active i.e the Back Arc Trust in the north and the subduction zone of the Indo-Australian plate subducting into the Eurasian plate to the south. Denpasar municipality and vicinity is the administrative center of Bali province with the infrastructure diversity. This research was conducted to map the damage potential zones caused by earthquake using a single station microtremor measurement which was analyzed by using HVSR (Horizontal to Vertical Spectral Ratios) method and microtremor array were analyzed by using SPAC (Spacial Auto Correlation) method to get the value of $v_{s 30}$ (the shear waves velocity to a depth of $30 \mathrm{~m}$ ). The results showes that in Denpasar municipality and vicinity has a seismic vulnerability index values ranges from 0,103 to 33,78 , ground shear-strain values ranges from $7,00 \times 10^{-6}$ to $2,2 \times 10^{-3}$. Mean while, $v_{s 30}$ values ranges from 171,32 to $764,62 \mathrm{~m} / \mathrm{s}$. Based on SNI 1726:2012 and the reseach result, the classification of risk level earthquake showed that south Denpasar subdistrict has seismic vulnerability high scale (risk category I). Seismic vulnerability medium scale, i.e Kuta and west Denpasar subdistrict (risk category I, II, and III). Seismic vulnerability low areas, i.e east and north Denpasar, north Kuta, Mengwi, Sukawati, Kediri subdistrict (risk category I, II, III, and IV).

keywords: earthquake; Denpasar; microtremor; HVSR; $v_{s 30}$ 


\section{Pendahuluan}

Kotamadya Denpasar dan sekitarnya berada di Bali selatan dengan topografi permukaan yang landai dan berdekatan dengan beberapa pantai termasuk pantai hasil reklamasi. Hasil penelitian terdahulu menunjukan bahwa semakin dekat suatu daerah dengan bibir pantai, maka semakin besar resiko kerusakan akibat gempabumi [1]. Gempabumi Seririt tahun 1976 merupakan salah satu gempabumi besar yang pernah melanda provinsi Bali. Gempabumi ini menyebabkan korban jiwa sebanyak 573 orang meninggal, 4755 orang terluka, dan kerusakan bangunan dalam radius 50 kilometer dari pusat gempa seperti 226 sekolah, 85.500 rumah warga rusak. Meskipun di Kotamadya Denpasar dan sekitarnya jarang terjadi gempabumi, namun tingkat resiko akibat bencana gempabumi dapat meningkat karena faktor kepadatan penduduk, kerentanan infrastruktur, dan nilai substansial ekonomi daerah tersebut. Berdasarkan hal tersebut, diperlukan penelitian berupa pemetaan zona-zona yang berpotensi terhadap kerusakan akibat gempabumi. Kotamadya Denpasar merupakan daerah perkotaan sehingga penelitian yang paling cocok adalah penelitian dengan menggunakan metode geofisika pasif seperti pengukuran mikrotremor. Mikrotremor merupakan getaran alami yang dapat disebabkan oleh alam dan aktivitas manusia. Pengukuran mikrotremor single station dapat digunakan untuk mengetahui karakteristik dinamika tanah berdasarkan nilai frekuensi dominan $f_{0}$, amplifikasi $\mathrm{A}$, indeks kerentanan seismik $K_{g}$, ground shear-strain $\gamma$, sedangkan mikrotremor array digunakan untuk mengetahui ketebalan lapisan sedimen permukaan dan klasifikasi profil tanah (Classification Site) berdasarkan nilai kecepatan gelombang sekunder sedalam $30 \mathrm{~m} v_{s 30}$. Penelitian ini menggunakan data gempabumi Seririt tahun 1976 sebagai studi kasus untuk mencari nilai PGA (Peak Ground Acceleration) batuan dasar dan PGA lapisan tanah permukaan. Analisis data mikrotremor single station menggunakan metode HVSR (Horizontal to Vertical Spectral Ratios). Hasil analisis HVSR dan PGA batuan dasar digunakan untuk mencari nilai indeks kerentanan seismik dan ground shear-strain. Analisis data mikrotremor array menggunakan metode SPAC (Spacial Auto Correlation) untuk mendapatkan nilai $v_{s 30}$ (kecepatan gelombang shear sedalam $30 \mathrm{~m}$ ). Nilai $v_{s 30}$ digunakan untuk mengklasifikasi jenis tanah berdasarkan SNI 1726:2012.

Informasi lengkap tentang penulis dapat dilihat pada akhir artikel ${ }^{\dagger}$ Equal contributor

\section{Metode Penelitian}

Data mikrotremor diperoleh dari data pengukuran yang dilakukan oleh Tim Pusat Survei Geologi (PSG) Bandung pada bulan Mei-Juni dan bulan Oktober-November tahun 2014. Jumlah titik ukur adalah sebanyak 277 titik pengukuran mikrotremor single station menggunakan seismometer tipe Mark L4-3D dan 15 titik pengukuran mikrotremor array.

Pengolahan data single station menggunakan metode HVSR melalui software Geopsy. Pengolahan diawali dengan membuka data di software Geopsy yang masih dalam kawasan waktu. Kemudian dilakukan proses windowing yaitu memilih sinyal yang stasioner sesuai kriteria Sesame 2004.

Tahapan selanjutnya adalah memasukkan parameter pengolahan data pada kolom processing dalam menu $\mathrm{H} / \mathrm{V}$ toolbox. Parameter yang diisikan antara lain jenis smoothing Konno-Ohmachi beserta nilai bandwidhnya, nilai tapering, dan memilih squared average untuk perhitungan pada komponen horizontal. Kemudian tekan start untuk memproses data dan menghasilkan kurva HVSR. Pada puncak kurva HVSR terdapat nilai frekuensi dominan dan amplifikasi HVSR yang kemudian digunakan untuk menghitung indeks kerentanan seismik. Secara eksplisit metode HVSR memenuhi persamaan (1)

$$
\frac{S_{H S}}{S_{V S}}=\frac{\sqrt{\left(S_{\text {utara-selatan }}\right)^{2}+\left(S_{\text {barat-timur }}\right)^{2}}}{S_{\text {vertikal }}}
$$

Pengambilan data mikrotremor array dilakukan menggunakan 4 seismometer OYO model 1134 dengan konfigurasi berbentuk segitiga. Satu data mikrotremor array terdiri atas 5-6 data pengukuran dengan jarak antar seismometer $\mathrm{r}$ yang berbeda-beda. Jarak seismometer yang digunakan adalah $2 \mathrm{~m}, 5 \mathrm{~m}$, $7 \mathrm{~m}, 10 \mathrm{~m}, 20 \mathrm{~m}$. Pengukuran ke-6 dilakukan jika luas daerah pengukuran memungkinkan membuat konfigurasi dengan jarak antar seismometer $30-35 \mathrm{~m}$. Durasi tiap pengukuran antara 20-45 menit. Pada mikrotremor array pengukuran hanya dilakukan pada komponen vertikal.

Pengolahan data pengukuran mikrotremor array menggunakan metode SPAC (Spatial Auto Correlation) untuk menentukan kecepatan gelombang sekunder. Pengolahan data diawali dengan menggunakan software Geopsy dilanjutkan menggunakan program Spac2disp dan terakhir menggunakan program Dinver untuk memperoleh ground profile tiap titik pengukuran.

Analisis metode SPAC dilakukan dengan mentransformasikan data mikrotremor kawasan waktu ke dalam kawasan frekuensi pada seluruh 
sensor array kemudian korelasi data mikrotremor dihitung untuk tiap pasangan sensor. Korelasi dari seluruh pasangan sensor kemudian dihitung nilai rata-ratanya dan mendapatkan koefisien autokorelasi rata-rata (spektrum koherensi/koefisien SPAC). Menurut Robert dan Asten (2008), koefisien SPAC memenuhi persamaan fungsi Bessel orde nol seperti pada persamaan (2)

$$
\bar{c}(f)=J_{o}\left(\frac{2 \pi f r}{v(f)}\right)
$$

dengan adalah koherensi rata rata, $J_{o}$ adalah fungsi Bessel orde nol, $r$ adalah jarak antar stasiun pengukuran.

\section{Hasil dan Pembahasan}

Nilai frekuensi dominan yang didapatkan berkisar antara 0,569-14,236 Hz (Gambar ). Sebaran nilai $f_{0}$ secara umum bernilai tinggi di sebelah utara dan barat daerah penelitian meliputi Kecamatan Denpasar Barat, Kecamatan Denpasar Utara dan Kecamatan Kuta Utara. Secara geologi daerah ini termasuk formasi batuan gunungapi kelompok Buyan-Bratan dan Batur. Material dari formasi ini terdiri dari tufa pasiran, endapan lahar, breksi, kerikil. Di Kecamatan Kuta utara yang berbatasan dengan Samudera Hindia didominasi oleh materi berupa batuan sedimen gamping keras. Sebaran nilai $f_{0}$ rendah pada daerah penelitian terletak di sebelah selatan yaitu Kecamatan Denpasar Selatan dan Kecamatan Kuta. Daerah tersebut didominasi oleh material aluvium berupa kerikil, lanau, lempung serta endapan sungai dan danau. Nilai frekuensi dominan $f_{0}$ berasosiasi dengan kedalaman bedrock. Semakin rendah nilai $f_{0}$ maka semakin tebal lapisan sedimen tersebut [2].

Semakin tebal lapisan sedimen suatu daerah akan mengakibatkan amplifikasi saat terjadi gempabumi. Hal ini sesuai dengan sebaran nilai indeks kerentanan seismik $K_{g}$ daerah penelitian. Nilai $K_{g}$ berkisar antara 0,103-33,78. Peta sebaran nilai $K_{g}$ ditunjukan pada Gambar .

Sebaran intensitas gempabumi dapat diketahui dari parameter PGA (Peak Ground Acceleration). Penelitian ini menggunakan data gempabumi Seririt 1976, adapun peta PGA batuan dasar dapat dilihat pada Gambar. Nilai PGA tinggi di bagian utara dan semakin rendah ke selatan. Hal ini karena perhitungan nilai PGA menggunakan persamaan Fukushima-Tanaka (1990) yang bergantung pada magnitudo dan jarak hiposenter.

Profil tanah daerah penelitian diklasifikasikan berdasarkan SNI 1726:2012 dengan menggunakan nilai $v_{s 30}$ dari pengukuran mikrotremor array. Klasifikasi profil tanah Kotamadya Denpasar dan sekitarnya ditunjukan pada Tabel 1. Berdasarkan Tabel 1, Kecamatan Denpasar Selatan memiliki nilai $v_{s 30}$ yang rendah dengan jenis tanah berupa tanah lunak. Hal ini menandakan bahwa Kecamatan Denpasar Selatan memiliki potensi paling besar terhadap kerusakan akibat gempabumi dibandingkan kecamatan yang lain.

Pemetaan daerah rawan kerusakan akibat gempabumi di Kotamadya Denpasar dan sekitarnya dilakukan berdasarkan perhitungan dan analisis nilai ground shear-strain, indeks kerentanan seismik, dan ketebalan lapisan sedimen. Ketiga parameter ini berhubungan dengan deformasi tanah yang menyebabkan kerusakan bangunan dan infrastruktur yang ada di dalam maupun di permukaan tanah. Peta daerah rawan kerusakan akibat gempabumi ditunjukan oleh Gambar . Tingkat kerawanan seismik tinggi ditandai dengan warna merah, untuk tingkat kerawanan menengah ditandai dengan warna oranye dan daerah dengan tingkat kerawanan seismik rendah ditandai dengan warna kuning. Dalam kaitannya dengan rencana tata ruang dan wilayah Kotamadya Denpasar dan sekitarnya, peta daerah rawan kerusakan akibat gempabumi digunakan sebagai rekomendasi yang bersifat umum berdasarkan SNI 1726:2012. Penelitian ini tidak memberikan rekomendasi tipe dan desain bangunan yang sudah ada ketentuannya.

Tabel 1: Sebaran nilai dan jenis batuan daerah penelitian.

\begin{tabular}{|c|c|c|c|}
\hline $\begin{array}{c}\text { Nama } \\
\text { titik }\end{array}$ & $\begin{array}{c}v_{s 30} \\
(\mathrm{~m} / \mathrm{s})\end{array}$ & Jenis tanah & Kecamatan \\
\hline $\mathrm{A} 001$ & 345.72 & tanah sedang & Mengwi \\
$\mathrm{A} 002$ & 387.75 & tanah keras, batuan lunak & Sukawati \\
$\mathrm{A} 003$ & 662.42 & tanah keras, batuan lunak & Kuta \\
$\mathrm{A} 004$ & 738.63 & tanah keras, batuan lunak & Kuta \\
$\mathrm{A} 005$ & 327.75 & tanah sedang & Denpasar Timur \\
$\mathrm{A} 006$ & 764.62 & batuan & Denpasar Timur \\
$\mathrm{A} 007$ & 640.50 & tanah keras, batuan lunak & Denpasar Barat \\
$\mathrm{A} 008$ & 425.68 & tanah keras, batuan lunak & Denpasar Timur \\
$\mathrm{A} 009$ & 726.96 & tanah keras, batuan lunak & Denpasar Timur \\
$\mathrm{A} 010$ & 325.62 & tanah sedang & Denpasar Selatan \\
$\mathrm{A} 011$ & 694.54 & tanah keras, batuan lunak & Mengwi \\
$\mathrm{A} 012$ & 243.01 & tanah sedang & Denpasar Selatan \\
$\mathrm{A} 013$ & 171.32 & tanah lunak & Denpasar Selatan \\
$\mathrm{A} 014$ & 273.96 & tanah sedang & Denpasar Timur \\
$\mathrm{A} 015$ & 367.26 & tanah keras, batuan lunak & Kuta \\
\hline
\end{tabular}

\section{Kesimpulan}

Berdasarkan hasil dan pembahasan yang sudah diuraikan pada bab sebelumnya, dapat diperoleh kesimpulan sebagai berikut:

1 (a) Berdasarkan peta sebaran indeks kerentanan seismik, nilai indeks kerentanan seismik berkisar antara 0,103-33,78. Nilai $K_{g}$ 


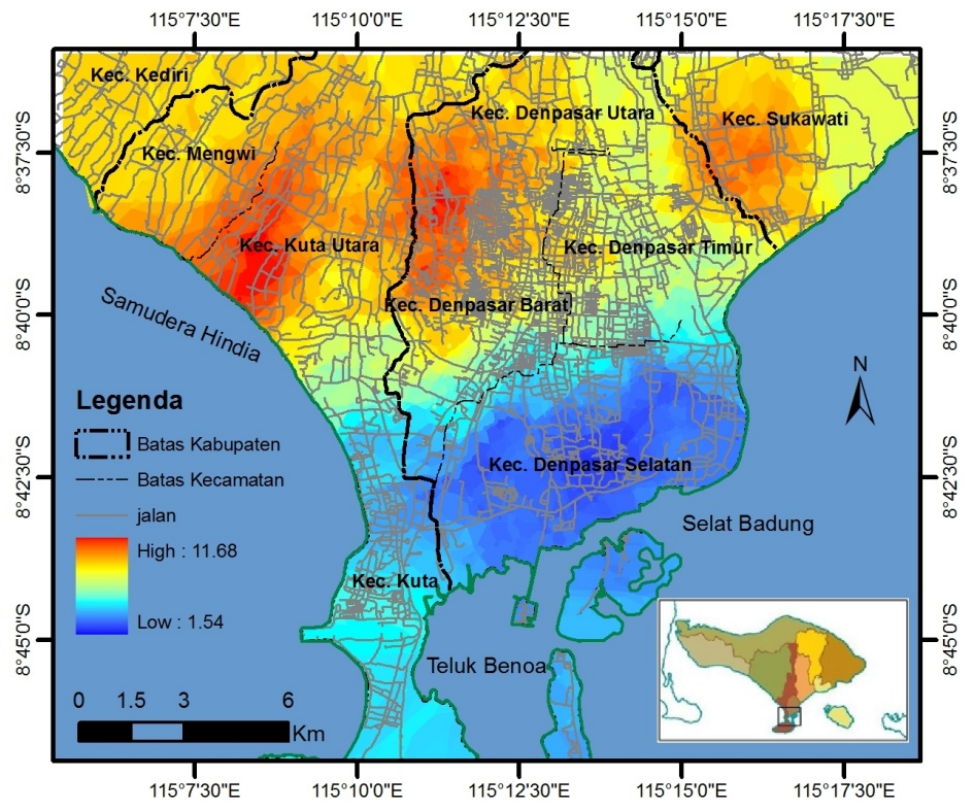

Gambar 1: Peta sebaran nilai frekuensi dominan

di Kecamatan Denpasar Timur adalah 0,10-13,12, nilai $K_{g}$ Kecamatan Denpasar Barat 0,30-24,12, Kecamatan Kuta memiliki nilai $0,39-18,35$. Nilai $K_{g}$ di Kecamatan Mengwi berkisar 0,40-29,69, Kecamatan Kuta Utara berkisar 0,35-20,48, Nilai $K_{g}$ Kecamatan Denpasar Utara yaitu 0,32-16,83. Nilai $K_{g}$ tinggi berada di Kecamatan Denpasar Selatan yaitu 0,29-33,78.

(b) Berdasarkan peta sebaran ground shear-strain, nilai ground shear-strain berkisar antara dengan nilai rata-rata antara berada di seluruh daerah penelitian.

2 Berdasarkan peta sebaran $v_{s 30}$, nilai $v_{s 30}$ berkisar antara 171,32-764,62 m/s. Kecamatan Denpasar selatan memiliki nilai $v_{s 30}$ rendah. Daerah ini merupakan pantai reklamasi dan berisi tanah aluvium.

3 Potensi kerusakan infrastruktur berkaitan erat dengan karakteristik gerakan tanah dan klasifikasi tanah. Berdasarkan hasil analisis, Kecamatan Denpasar Selatan memiliki potensi kerusakan paling tinggi dibandingkan dengan kecamatan lainnya. Berdasarkan hasil analisis $v_{s 30}$, jenis tanah di Kecamatan Denpasar Selatan berupa tanah lunak.

4 Berdasarkan SNI 1726:2012 dan hasil analisis, tingkat kerawanan seismik di Kotamadya
Tabel 2: Tingkat kerawanan seismik daerah penelitian.

\begin{tabular}{|c|c|c|}
\hline Kecamatan & $\begin{array}{c}\text { Tingkat kerawanan } \\
\text { seismik }\end{array}$ & $\begin{array}{l}\text { Kategori resiko } \\
\text { (SNI 1726:2012) }\end{array}$ \\
\hline Denpasar Utara & Rendah & I, II, III dan IV \\
\hline Denpasar Selatan & Tinggi & \\
\hline Denpasar Barat & $\begin{array}{l}\text { Sedang, Tinggi, } \\
\text { Dominan rendah }\end{array}$ & I, II, dan III \\
\hline $\begin{array}{c}\text { Denpasar Timur } \\
\text { Kuta }\end{array}$ & $\begin{array}{c}\text { Rendah } \\
\text { Sedang, } \\
\text { Dominan rendah }\end{array}$ & $\begin{array}{l}\text { I, II, III dan IV } \\
\text { I, II, dan III }\end{array}$ \\
\hline Kuta Utara & Rendah & I, II, III dan IV \\
\hline Mengwi & Rendah & I, II, III dan IV \\
\hline Kediri & Rendah & I, II, III dan IV \\
\hline Sukawati & Rendah & I, II, III dan IV \\
\hline
\end{tabular}

Denpasar dan sekitarnya ditunjukan pada Tabel 2 .

\section{Informasi penulis}

${ }^{1}$ Department of Physics, Universitas Gadjah Mada, Sekip Utara PO BOX BLS 21, 55281 Yogyakarta, Indonesia. ${ }^{2}$ Pusat Survei Geologi, Kementerian ESDM, Bandung, Indonesia.

\section{Pustaka}

1. Nakamura, Y.: Seismic vulnerability indices for ground and structures using microtremor. In: World Congress on Railway Research, Florence (1997). World Congress on Railway Research

2. Parolai, B.P. S, Milkert, C.: Assessment of the natural frequency of the sedimentary cover in the cologne area (germany) using noise measurements. Journal of

Earthquake Engineering 5 (2001) 


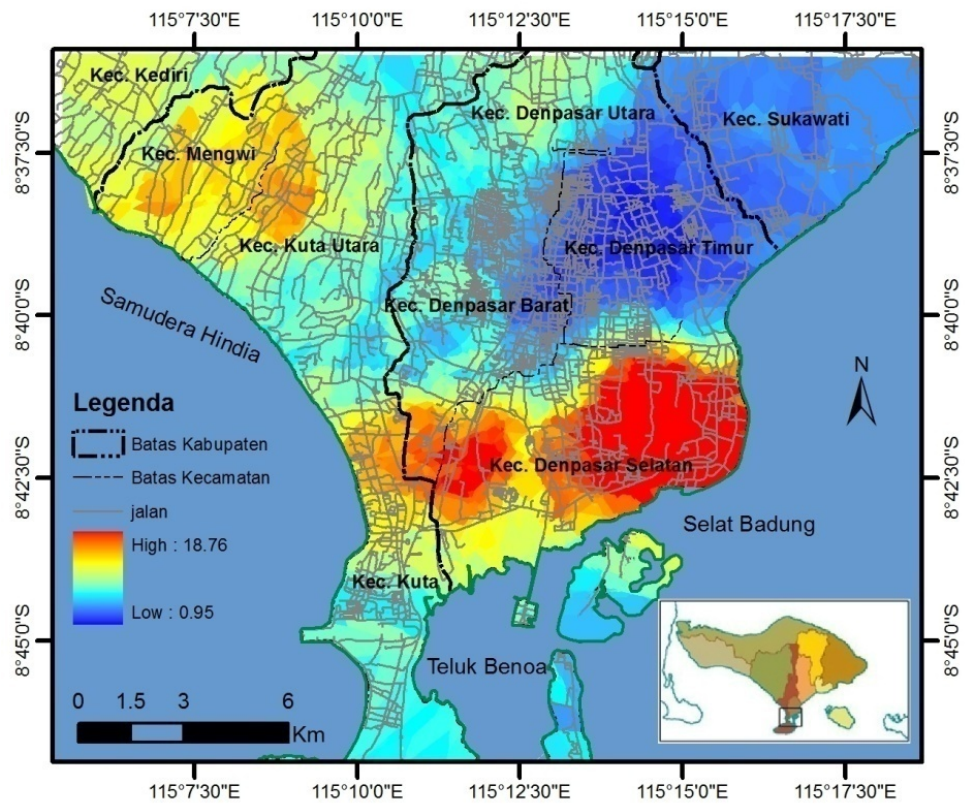

Gambar 2: Peta sebaran nilai indeks kerentanan seismik

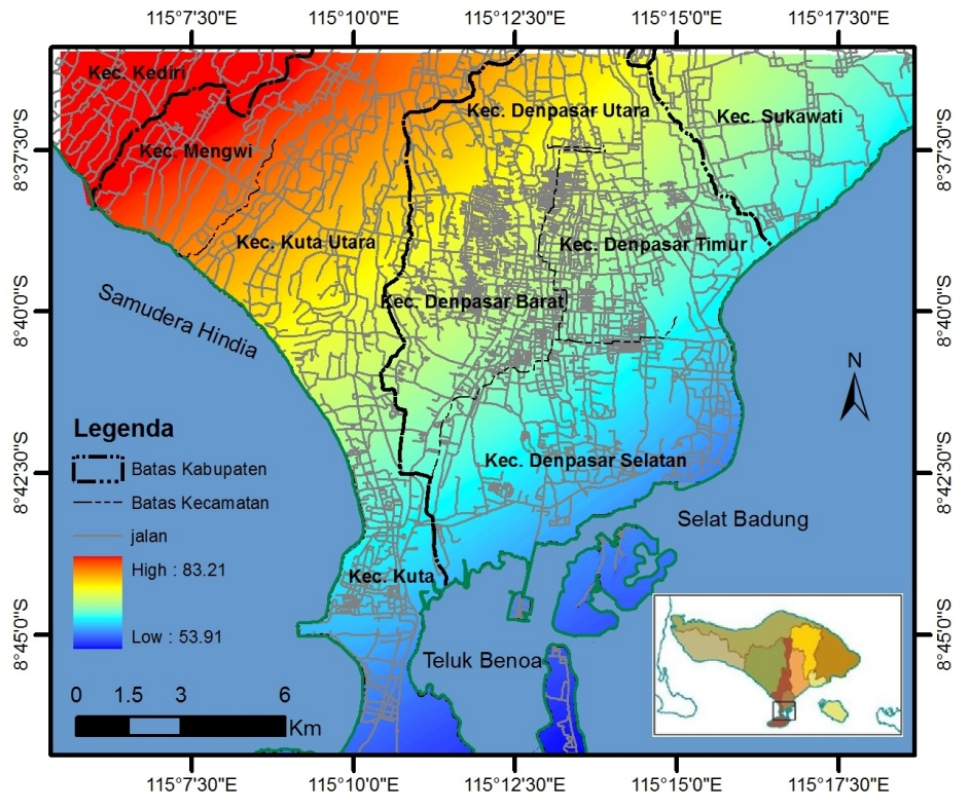

Gambar 3: Peta sebaran nilai PGA batuan dasar 


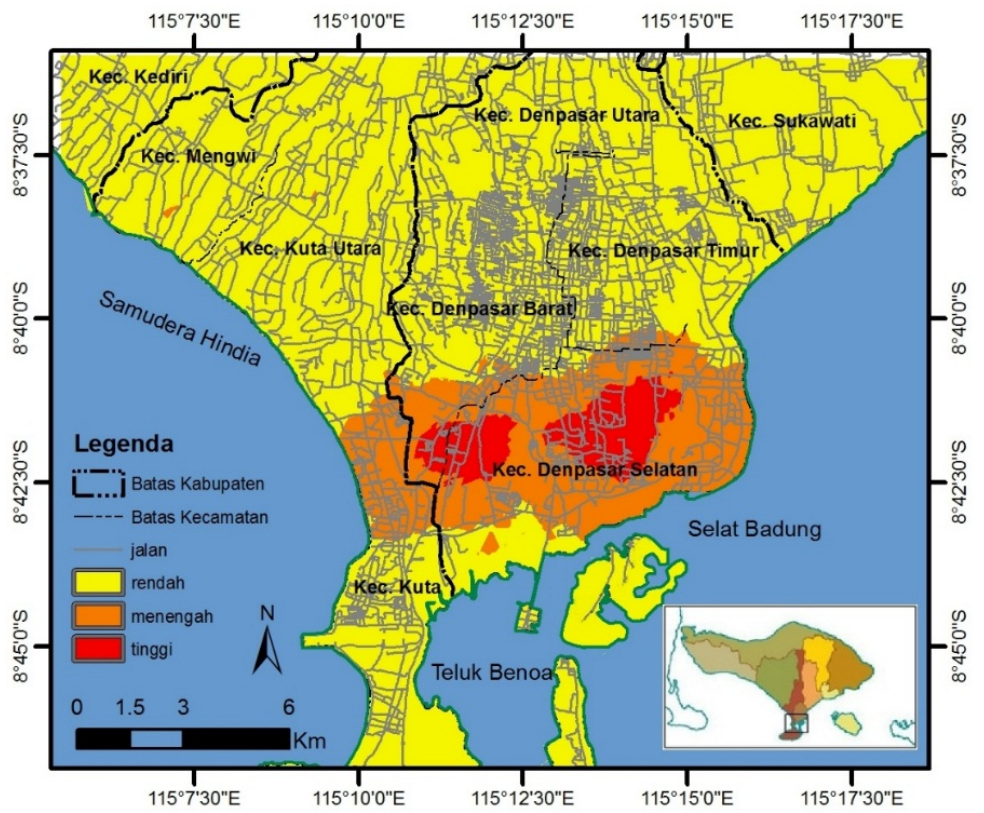

Gambar 4: Peta daerah rawan kerusakan akibat gempabumi Kotamadya Denpasar dan sekitarnya. 